\title{
A Rapid Greenhouse Screening Method to Identify St. John's Wort (Hypericum perforatum) Accessions Resistant to Colletotrichum gloeosporioides
}

\author{
Vincent V. Michel ${ }^{1}$ \\ Agroscope, CH-1964 Conthey, Switzerland \\ Nicole Debrunner and Xavier Simonnet \\ Médiplant, CH-1964 Conthey, Switzerland
}

Additional index words. anthracnose, disease, Hypericum perforatum, resistance breeding

\begin{abstract}
Anthracnose is a major production constraint for st. john's wort (Hypericum perforatum L.) caused by the fungus Colletotrichum gloeosporioides (Penz.). A greenhouse screening method based on mortality was developed to eliminate accessions susceptible to anthracnose in the early stage of breeding for resistant cultivars. The mortality of 22 accessions of st. john's wort artificially inoculated with a strain of $C$. gloeosporioides was highly correlated between three greenhouse experiments $(r=0.799$ to 0.923$)$, even when done at two different places. The response of the greenhouse screening was equally highly correlated to the mortality in the field tested at two sites naturally infested with $C$. gloeosporioides $(r=0.700$ to 0.865$)$ but less well correlated with the mortality at a third field site $(r=0.495$ to 0.672$)$. Yield of st. john's wort was highly correlated with mortality $(r=-0.747$ to -0.846$)$ at all three field sites, but a significant interaction between accession and site was observed. Therefore, an improvement of anthracnose resistance of st. john's wort should be based on a greenhouse screening of seedlings followed by multiple-site field testing of adult plants.
\end{abstract}

The intensification of the st. john's wort (Hypericum perforatum) production in Switzerland at the end of the 1990s was accompanied by the appearance of anthracnose caused by Colletotrichum gloeosporioides (teleomorph Glomerella cingulata) (Debrunner et al., 2000), an important fungal disease of st. john's wort (Crompton et al., 1988). Reports on the occurrence of the disease in several European countries (Bomme, 1997; Debrunner et al., 2000; Schwarczinger and Vajna, 1998) can be related to the rapidly increasing surfaces planted to $H$. perforatum, largely attributable to the growing popularity of st. john's wort-based antidepressive drugs (Müller, 2005). For mild to moderate depression, Hypericum extracts show a similar efficacy and a better tolerability compared with standard antidepressant drugs (Kasper et al., 2010). The intensification of st. john's wort production led to a shift in the production mode to supply sufficient quantities of inflorescences needed for the transformation in herbal medicine. Wild collection was replaced by field cultivation to produce large quantities in a rational way and to protect natural populations (Lange, 2004). As a consequence of this intensive production, C. gloeosporioides became a major problem, especially in organic farming with

Received for publication 30 July 2013. Accepted for publication 31 Oct. 2013.

${ }^{1}$ To whom reprint requests should be addressed; e-mail vincent.michel@agroscope.admin.ch. a restricted use of fungicides, as is the case in the major part of the st. john's wort fields grown in Switzerland (Debrunner et al., 2000). Under such conditions, the pathogen can destroy this perennial crop in the first year of cultivation, especially when planted in more humid production areas and in heavy soils.

Because we are still at the beginning of the domestication process, breeding for anthracnose resistance offers the most promising way to reduce the impact of this disease, even in conventional farming systems. A breeding program was set up by Médiplant, a Swiss research and development institution focusing on the promotion of herbal and aromatic plants, with special emphasis on mountainous environments (Simonnet and Gaudin, 2000). From 1997 to 1999, a first step in st. john's wort improvement was achieved by screening 24 accessions in three different environments, resulting in the release of a resistant cultivar (Gaudin et al., 2002). However, field selection under natural infection with $C$. gloeosporioides is time- and spaceconsuming. Furthermore, conditions that are favorable for a natural infection vary from 1 year to the other, which can result in insufficient disease pressure in some years. A solution to this problem is the screening in the greenhouse for disease resistance before testing the more advanced breeding material under field conditions (Gardner, 1990).

The objective of this study was the development of a rapid greenhouse screening method for the identification of st. john's wort accessions that are resistant to anthracnose caused by $C$. gloeosporioides.

\section{Materials and Methods}

Accessions. Of the 26 st. john's wort accessions tested, 19 were used for both the greenhouse and field experiments. Additional two and five accessions were included in the greenhouse and field experiments, respectively. Next to the commercial cultivars, Topaz (Poland), Hyperimed (Germany), and Elixir (Canada), accessions from Switzerland (16 accessions), Germany (two accessions), Spain (two accessions), Australia (one accession), Austria (one accession), and Italy (one accession) were tested.

Seeds of the accessions were sown in multipot trays containing a commercial peat substrate (Brill $1+$ Tonerde; Gebr. Brill Substrate $\mathrm{GmbH} \& \mathrm{Co}$, Georgsdorf, Germany) and were placed in a greenhouse at $20^{\circ} \mathrm{C}$ with a relative air humidity of $80 \%$. Additional light was supplemented during the day by fluorescent tubes for $14 \mathrm{~h}$. After emergence of the cotyledons, temperature was maintained at $20^{\circ} \mathrm{C}$ during the day but was lowered to $15^{\circ} \mathrm{C}$ during night. After 3 weeks, single seedlings at the two-true-leaf stage were transplanted in plastic pots $(6 \times 6 \mathrm{~cm}, 5 \mathrm{~cm}$ depth $)$ containing a commercial peat substrate.

Inoculum. The C. gloeosporioides strain AN-16 was used to prepare the spore suspension for artificial inoculation in the greenhouse. This strain was isolated from a typical anthracnose stem lesion on st. john's wort at Conthey (Switzerland) and was identified based on morphological characteristics (Mordue, 1971) after growth on potato dextrose agar (PDA) and under light microscope. The identification was confirmed by the CABI Microbial Identification Service (Egham, U.K.). The strain was stored on PDA at $4{ }^{\circ} \mathrm{C}$ and periodically subcultured.

Spores were produced in a modified Richard's solution (Daniel et al., 1973). Two to three PDA cubes with mycelium were added to $100-\mathrm{mL}$ aliquots in $300-\mathrm{mL}$ Erlenmeyer flasks. They were placed on a rotary shaker (100 rpm) and incubated at room temperature for $5 \mathrm{~d}$. Spores were harvested by filtration through cheesecloth followed by two consecutive centrifugations at $3913 g_{n}$ with resuspension of the pellets in $10 \mathrm{~mL}$ sterile deionized water (Daniel et al., 1973). Final concentration of the suspension was adjusted to $1 \times 10^{7}$ spores $/ \mathrm{mL}$ by counting spores under light microscope using a counting chamber.

Greenhouse experiments. Artificial inoculation of 22 accessions was done twice in a greenhouse of the Agroscope crop improvement program at Nyon (Expt. ACW \#1 and ACW \#2) and once at Conthey (Expt. Médiplant) (Table 1). The experimental layout was a randomized complete block design (RCBD) with three replicates. At Nyon, each replicate was placed in a separate greenhouse compartment and consisted of 10 individual plants per accession. At Conthey, three replicates of five individual plants were all placed in the same greenhouse compartment. Plants 
Table 1. Mortality (\%) of 26 st. john's wort accessions in the greenhouse after artificial inoculation with Colletotrichum gloeosporioides in the greenhouse and natural infection in the field at three sites.

\begin{tabular}{|c|c|c|c|c|c|c|}
\hline \multirow[b]{2}{*}{ St. john's wort accession } & \multicolumn{3}{|c|}{ Greenhouse experiments ${ }^{2}$} & \multicolumn{3}{|c|}{ Field experiments ${ }^{y}$} \\
\hline & ACW \#1 & ACW \#2 & Médiplant & Bruson & Epines & $\overline{\text { Fougères }}$ \\
\hline Topaz & 41 & 30 & 60 & 0 & 3 & 3 \\
\hline Hyperimed & 69 & $0^{\mathrm{x}}$ & 100 & 10 & 27 & 23 \\
\hline Elixir & 23 & 7 & 33 & 7 & 23 & 33 \\
\hline Нp \#4 & $\mathrm{nt}^{\mathrm{w}}$ & nt & nt & 17 & 87 & nt \\
\hline Нp \#5 & nt & nt & nt & 100 & 100 & 100 \\
\hline Нp \#6 & 100 & 100 & 100 & 100 & 83 & nt \\
\hline Нp \#7 & 3 & 0 & 0 & 0 & 0 & 10 \\
\hline Нp \#8 & 86 & 41 & 93 & 53 & 87 & nt \\
\hline Нp \#9 & 100 & 100 & 100 & 100 & 100 & 100 \\
\hline Hp \#10 & 100 & 100 & 100 & 100 & 100 & nt \\
\hline Нp \#11 & 100 & 100 & 100 & 100 & 100 & 100 \\
\hline Нp \#12 & 90 & 23 & 27 & 40 & 80 & 40 \\
\hline Нp \#13 & 100 & 100 & 100 & 100 & 100 & 100 \\
\hline Hp \#14 & 100 & 100 & 100 & 100 & 100 & 100 \\
\hline Hp \#15 & 100 & 100 & 100 & 100 & 100 & 100 \\
\hline Нp \#16 & 96 & 60 & 100 & 27 & 100 & 27 \\
\hline Нp \#17 & 43 & 3 & 27 & 0 & 0 & nt \\
\hline Нp \#18 & 93 & 90 & 80 & 0 & 17 & 20 \\
\hline Нp \#19 & $\mathrm{nt}$ & $\mathrm{nt}$ & $\mathrm{nt}$ & 0 & 23 & 50 \\
\hline Hp \#20 & 93 & 50 & 87 & 0 & 93 & 60 \\
\hline Hp \#21 & 3 & 0 & 7 & 0 & 27 & 30 \\
\hline Нp \#22 & $\mathrm{nt}$ & $\mathrm{nt}$ & $\mathrm{nt}$ & 27 & 100 & 83 \\
\hline $\mathrm{Hp} \mathrm{\# 23}$ & $\mathrm{nt}$ & $\mathrm{nt}$ & nt & 3 & 100 & nt \\
\hline Нp \#24 & 100 & 73 & 100 & 0 & 100 & 20 \\
\hline Hp \#201 & 87 & 90 & 100 & nt & nt & nt \\
\hline Нp \#208 & 57 & 40 & 73 & nt & nt & nt \\
\hline
\end{tabular}

${ }^{\mathrm{z}}$ Two experiments were conducted in the greenhouse of Agroscope Changins-Wädenswil at Nyon (ACW) and one in the greenhouse of Médiplant at Conthey. Mortality was rated 3 weeks after inoculation.

${ }^{y}$ Experiments were planted in Spring 1997 at the three sites natural infection of Colletotrichum gloeosporioides. Mortality was rated at harvest in Summer 1998.

${ }^{\times}$Number in italic $=$only one replicate of 10 plants (instead of three replicates).

${ }^{\mathrm{w}} \mathrm{nt}=$ not tested.

were inoculated 8 to 10 weeks after transplanting; plant height varied from 15 to $30 \mathrm{~cm}$ depending on the accession. The spore suspension, supplemented with $1 \mathrm{~mL} / \mathrm{L}$ Tween 20 as a surfactant, was sprayed on the plants until runoff by the means of a handheld sprayer. A volume of $150 \mathrm{~mL}$ of spore suspension was needed to inoculate 220 plants, the equivalent of one replicate in the experiments at Nyon. After inoculation, plants were left in the greenhouse compartments and highly conducive conditions were created for $48 \mathrm{~h}$. Therefore, the relative air humidity was set to $100 \%$ using a cold mist humidifier. During this period, the fluorescent tubes were removed. Air temperature was set to $24 / 20^{\circ} \mathrm{C}$ (day/night, 14-h photoperiod) until the rating of mortality 3 weeks after inoculation. Plants were considered dead when the aboveground part of the plant was completely dry, with the exception of new sprouts growing from the basal part of the plant. Expts. ACW \#1 and ACW \#2 were conducted with 1 week interval at Nyon with inoculation on 19 and 26 Jan. 1999 for Expt. ACW \#1 and ACW \#2, respectively. Expt. Médiplant conducted at Conthey was inoculated on 15 Feb. 2000.

Field experiments. The sites for field experiments were located at Bruson (1060 m a.s.l.), Fougères, and Epines (both at $480 \mathrm{~m}$ a.s.1.). All three sites are situated in the mountainous canton (= state) of Valais in the southern part of Switzerland, the latter two sites in the main valley and Bruson in a side valley. At Bruson and Epines, 10- to 11-week-old seedlings of
Harvest in 1998 occurred between 6 July and 4 August, 17 June and 13 July, and 9 June and 9 July at Bruson, Epines, and Fougères, respectively. At harvest, the top $15 \mathrm{~cm}$ of the inflorescences was collected manually and dry matter yield per experimental plot was determined. The resistance to the natural $C$. gloeosporioides infection in the field was assessed before the harvest in 1998 by recording the number of dead plants. At all three sites, no other disease than anthracnose and no infestation by insect pests were observed during the 2 years of cultivation.

Statistical analysis. The mortality rate of the st. john's wort accessions in the greenhouse and field experiments were compared by Spearman rank order correlation analysis imposed by the non-normal distribution even after arcsine transformation of the data (Little and Hills, 1978). Yield of the experimental plots was used as a basis for an analysis of variance to measure the influence of the accession and site on the dry matter production. The effect of the mortality in the field on yield was analyzed using Pearson product moment correlation analysis.

\section{Results}

The resistance of the st. john's wort accessions to anthracnose varied greatly in both the greenhouse and field experiments (Table 1). Highly susceptible accessions in the greenhouse (i.e., with $100 \%$ mortality in all three experiments) were also highly susceptible in the field (Hp \#6, \#9 to $11, \# 13$ to 15 ) with at least $83 \%$ mortality. Two accessions (Hp \#7 and \#21) had less than $10 \%$ mortality in the greenhouse. In the field, however, the reaction of these presumably highly resistant accessions was less clear cut. Hp \#7 was highly resistant, whereas the mortality of $\mathrm{Hp} \mathrm{\# 21}$ reached $30 \%$ at one site. In contrast, 'Topaz' and $\mathrm{Hp} \# 17$, with an average mortality in the greenhouse of $44 \%$ and $24 \%$, respectively, were highly resistant in the field.

The method to screen anthracnose resistance in the greenhouse using artificial inoculation proved to be consistent (Table 2). When the same material was tested twice at the same place (Nyon), the rank correlation coefficient was very high with $92 \%(P<$ $0.001)$, and screening at two different sites (Nyon and Conthey) by different persons was still highly correlated with at least $79 \%(P<$ 0.001). At two sites, Bruson and Epines, mortality in the field was highly correlated with a rank correlation coefficient of at least $70 \%(P<0.001)$ with the greenhouse screenings. Mortality at the site Fougères had a lower rank correlation coefficient and was not significant for the greenhouse screening experiment at Médiplant.

Dry matter production was significantly affected by the field site and the accession (Table 3). Mortality in the field had a direct impact on the dry matter yield in the second year after planting (Fig. 1). Dry matter yield was significant negatively correlated $(P<0.01)$ at all three sites, but ranking of the accessions was site-specific (Table 4). St. john's wort 
Table 2. Rank correlation coefficients of mortality ratings of st. john's wort accessions in three greenhouse and three field experiments.

\begin{tabular}{lcccccc}
\hline & \multicolumn{2}{c}{ Greenhouse experiments $^{\mathrm{z}}$} & & \multicolumn{3}{c}{ Field experiments $^{\mathrm{y}}$} \\
\cline { 2 - 3 } \cline { 5 - 7 } & ACW \#2 & Médiplant & & Bruson & Epines & Fougères \\
\hline ACW \#1 & $0.923^{* * * x}$ & $0.855^{* * *}$ & & $0.726^{* * *}$ & $0.865^{* * *}$ & $0.657^{* *}$ \\
ACW \#2 & - & $0.799^{* * *}$ & & $0.752^{* * *}$ & $0.775^{* * *}$ & $0.672^{* *}$ \\
Médiplant & & - & & $0.700^{* * *}$ & $0.828^{* * *}$ & $0.495 \mathrm{NS}$ \\
Bruson & & & & - & $0.698^{* * *}$ & $0.829^{* * *}$ \\
Epines & & & & - & $0.727^{* * *}$ \\
\hline
\end{tabular}

${ }^{2}$ Two experiments were conducted in the greenhouse of Agroscope Changins-Wädenswil at Nyon (ACW) and one in the greenhouse of Médiplant at Conthey. Mortality was rated 3 weeks after artificial inoculation. ${ }^{y}$ Experiments were planted in Spring 1997 at the three sites with natural infection of Colletotrichum gloeosporioides. Mortality was rated at harvest in Summer 1998.

${ }^{\times}$Correlation coefficients followed by $* * *, * *$, or Ns are significant at $P<0.001, P<0.01$, or nonsignificant $(P>0.05)$, respectively.

Table 3. Effect of st. john's wort accession and site on dry matter yield in the field.

\begin{tabular}{lrrrc}
\hline & df & \multicolumn{1}{c}{ MS } & F-value & Prob. $>$ F \\
\hline Block & 2 & 15081.4 & 0.4751 & 0.6236 \\
Accession & 16 & 321454.3 & 10.1259 & 0.0001 \\
Site & 2 & 530509.3 & 16.7111 & 0.0001 \\
Accession $\times$ site & 22 & 60410.3 & 1.9029 & 0.0201 \\
Error & 80 & 31745.9 & & \\
\hline
\end{tabular}

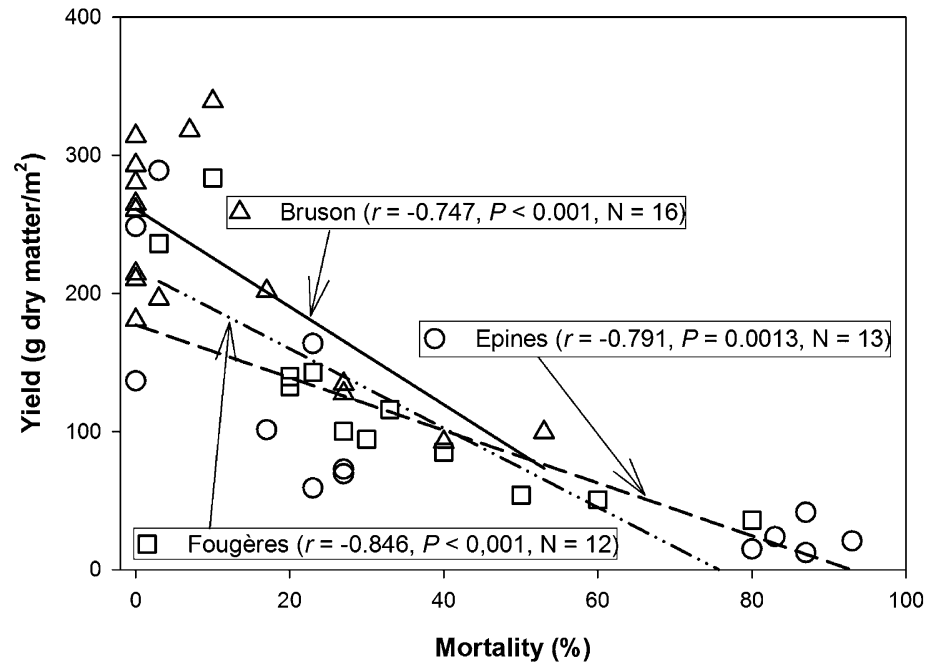

Fig. 1. Correlation between dry matter yield and mortality for the 1998 harvest of st. john's wort accessions in field experiments at three sites. Mortality was measured as percentage of dead plants (i.e., completely dry) before harvest. Accessions with $100 \%$ mortality were excluded from correlation analysis. For better visualization, non-transformed mortality data were used for graphical display, because correlation analysis with arcsine-transformed mortality data only differed slightly from the analysis using non-transformed data.

cultivar Hyperimed ranked at the highest position at Bruson and at the seventh position at Epines, whereas 'Topaz' was best at Epines and sixth at Bruson. Despite similar groups of accessions with high ('Topaz', 'Hyperimed', 'Elixir', Hp \#7, \#17, and \#18) and low (Hp \#6, \#8, \#12,\#16, \#20, and \#22) dry matter yield at the three sites, significant interactions $(P=0.02)$ between accession and site were observed (Table 3 ).

\section{Discussion}

Considerable differences in resistance of st. john's wort to anthracnose could be detected in the greenhouse after artificial inoculation with a spore suspension. The wide range of resistance stretching from complete
For the mass selection of st. john's wort, inoculation with $C$. gloeosporioides may take place before transplanting seedlings in pots, which would result in an important reduction of space and labor input. Highly susceptible accessions would thereby be eliminated before the labor-consuming transplanting. Before using such a mass screening scheme, however, the susceptibility of $H$. perforatum to $C$. gloeosporioides at different growing stages must be elucidated. Differences of susceptibility at the seedling stage were observed in cucumber (Cucumis sativus), where seedlings at the cotyledon stage were less susceptible to gummy stem blight than seedlings with one true leaf, which in their turn were less susceptible than seedlings with three true leaves (Amand and Wehner, 1995).

The major part of the st. john's wort accessions was collected in a relatively small area of Switzerland. The range of resistance levels represented by this sample indicates wide variability of this trait. Such a large variability in mortality of st. john's wort accessions was reported from Australia where several Australian and Canadian ecotypes were inoculated with two strains of $C$. gloeosporioides (Shepherd, 1995). For crop improvement purpose, such variability is of great interest, which gains additionally in value for the facultative apomictic st. john's wort (Mártonfi et al., 1996). Intra- and interspecific hybridizations of $H$. perforatum are difficult and ploidy level of the offspring can vary considerably (Schulte et al., 1999). The broad genetic diversity of st. johns' wort, as expressed in large variability in resistance to anthracnose, encourages therefore an improvement by selection of ecotypes rather than pedigree breeding.

If the first screening is done in the greenhouse, the results have to be transposable to field conditions. The high rank correlation coefficients between the greenhouse and the field experiments (Table 2) indicate that the level of resistance detected in the greenhouse after artificial inoculation is also valid in the field under natural infection. The only nonsignificant rank correlation coefficient between the Fougères field experiment and the Médiplant greenhouse experiment might be the result of the lower number of accessions tested at Fougères and the smaller number of plants per accession used in the Médiplant greenhouse experiment, which increased the variation of the results. All the remaining eight rank correlation coefficients varied between 0.865 and 0.657 and were highly significant. A slightly higher correlation coefficient of 0.89 was reported by Pande et al. (2011) between the screening of chickpea seedlings in the greenhouse and adult plants in the field for their resistance to Ascochyta blight caused by Ascochyta rabiei (Pass.) Labr. This higher correlation coefficient can be explained by the repeated artificial inoculation of the chickpea with a spore suspension of $A$. rabiei in the field. In contrast, our field screening of $H$. perforatum was conducted in plots naturally infested with $C$. gloeosporioides without additional inoculation. 
Table 4. Dry matter yield $\left(\mathrm{g} / \mathrm{m}^{2}\right)$ of 17 st. john's wort accessions at three sites with natural infection of Colletotrichum gloeosporioides in Summer 1998. ${ }^{\mathrm{z}}$

\begin{tabular}{|c|c|c|c|c|c|c|}
\hline \multirow[b]{2}{*}{ St. john's wort accession ${ }^{y}$} & \multicolumn{2}{|c|}{ Bruson } & \multicolumn{2}{|c|}{ Epines } & \multicolumn{2}{|c|}{ Fougères } \\
\hline & Yield & $\overline{\text { Rank }}$ & Yield & $\overline{\text { Rank }}$ & Yield & Rank \\
\hline Topaz & $265 \mathrm{abcd}^{\mathrm{x}}$ & 6 & $289 \mathrm{a}$ & 1 & $236 \mathrm{ab}$ & 2 \\
\hline Hyperimed & $339 \mathrm{a}$ & 1 & $69 \mathrm{bc}$ & 7 & $143 \mathrm{abc}$ & 3 \\
\hline Elixir & $318 \mathrm{ab}$ & 2 & $164 \mathrm{abc}$ & 3 & $116 \mathrm{bc}$ & 6 \\
\hline Нp \#4 & 202 abcde & 10 & $41 \mathrm{c}$ & 9 & $\mathrm{nt}^{\mathrm{w}}$ & \\
\hline Hp \#6 & 0 & & $24 \mathrm{c}$ & 10 & nt & \\
\hline $\mathrm{Hp} \# 7$ & $280 \mathrm{abc}$ & 5 & $248 \mathrm{ab}$ & 2 & $284 \mathrm{a}$ & 1 \\
\hline Нp \#8 & $99 \mathrm{e}$ & 15 & $12 \mathrm{c}$ & 13 & $\mathrm{nt}$ & \\
\hline Hp \#12 & $92 \mathrm{e}$ & 16 & $15 \mathrm{c}$ & 12 & $85 \mathrm{bc}$ & 9 \\
\hline Hp \#16 & $135 \mathrm{cde}$ & 13 & 0 & & $100 \mathrm{bc}$ & 7 \\
\hline Hp \#17 & $314 \mathrm{ab}$ & 3 & $137 \mathrm{abc}$ & 4 & nt & \\
\hline $\mathrm{Hp} \# 18$ & $293 \mathrm{ab}$ & 4 & $101 \mathrm{bc}$ & 5 & $133 \mathrm{abc}$ & 5 \\
\hline Hp \#19 & 214 abcde & 8 & $59 \mathrm{c}$ & 8 & $54 \mathrm{c}$ & 10 \\
\hline $\mathrm{Hp} \# 20$ & $181 \mathrm{bcde}$ & 12 & $21 \mathrm{c}$ & 11 & $51 \mathrm{c}$ & 11 \\
\hline $\mathrm{Hp} \# 21$ & 261 abcd & 7 & $73 \mathrm{bc}$ & 6 & $94 \mathrm{bc}$ & 8 \\
\hline $\mathrm{Hp} \mathrm{\# 22}$ & $128 \mathrm{de}$ & 14 & 0 & & $36 \mathrm{c}$ & 12 \\
\hline $\mathrm{Hp} \# 23$ & 196 abcde & 11 & 0 & & nt & \\
\hline $\mathrm{Hp} \# 24$ & 210 abcde & 9 & 0 & & $140 \mathrm{abc}$ & 4 \\
\hline
\end{tabular}

${ }^{\mathrm{z}}$ Experiments were planted in Spring 1997 and harvested in Summer 1998.

${ }^{y}$ Accessions Hp \#5, Hp \#9, Hp \#10, Hp \#11, Hp \#13, Hp \#14, and Hp \#15 had no yield at all the three sites and were therefore excluded from analysis.

${ }^{x}$ Numbers in columns followed by the same letter are not significantly different (Tukey test, $P=0.05$ ). Dry matter values of 0 were excluded from data analysis.

${ }^{\mathrm{w}} \mathrm{nt}=$ not tested.

The greenhouse tests were especially efficient in detecting highly susceptible accessions in the field. In contrast, the determination of resistant accessions in the field was not clearly linked to the response to artificial inoculation in the greenhouse (Table 1). Therefore, the greenhouse screening is suitable to discard the highly susceptible material, which allows a considerable decrease of the size of field tests. This second step of improvement is necessary not only to improve the anthracnose resistance, but also to measure agronomic traits such as yield, flowering date, growth type, cultivar stability, and phytochemical traits. Testing at multiple sites furthermore increases the quality of the field tests as the major factor that influences the SE between accessions is the environment (Campbell and Lipps, 1998).

The detection of susceptible accessions in the field is of major importance because the mortality is significantly correlated to the dry matter yield (Fig. 1). If important yield reduction caused by fungal pathogens is well known in crop production (Russell, 1978), loss of $100 \%$ yield resulting from a fungal disease is rather exceptional. This might be explained by the high susceptibility of some of the accessions tested. Another reason might be the augmentation of the pathogen population over a period of more than 1 year between planting and harvesting in the second year. A similar increase of the anthracnose pressure between the first and the second year of st. john's wort cultivation was also observed during cultivar tests in Germany (Schenk and Gärber, 2002). A rapid spread of the spores within the field experiments most probably occurred, because spores of C. gloeosporioides are reported to be easily dispersed by rainfall (Yang and TeBeest, 1992).

Field testing of selected accessions after greenhouse screening is stressed by the significant interactions between accessions and sites for dry matter yield (Table 3 ). Among the accessions tested at all three sites, the highest ranking Hp \#7 and 'Topaz' had the highest yield across all sites. In contrast, 'Hyperimed' and 'Elixir', belonging to the group with the highest yield at Bruson, had a significantly lower yield than the highest ranking accessions at Epines ('Hyperimed') and at Fougères ('Elixir'). For the use of a cultivar on a larger area, yield stability, as shown by 'Topaz' and Hp \#7, is of major importance (Plaisted and Peterson, 1959).

\section{Literature Cited}

Amand, P.C.St. and T.C. Wehner. 1995. Greenhouse, detached-leaf, and field testing methods to determine cucumber resistance to gummy stem blight. J. Amer. Soc. Hort. Sci. 120:673680.

Bomme, U. 1997. Produktionstechnologie von Johanniskraut (Hypericum perforatum L.). Z. Arzn. Gew. Pfl. 2:127-134.

Campbell, K.A.G. and P.E. Lipps. 1998. Allocation of resources: Sources of variation in Fusarium head blight screening nurseries. Phytopathology 88:1078-1086.

Crompton, C.W., I.V. Hall, K.I.N. Jensen, and P.D. Hildebrand. 1988. The biology of Canadian weeds. 83. Hypericum perforatum L. Can. J. Plant Sci. 68:149-162.

Daniel, J.T., G.E. Templeton, R.J. Smith, and W.T. Fox. 1973. Biological control of Northern jointvetch in rice with an endemic fungal disease. Weed Sci. 21:303-307.

Debrunner, N., A.-L. Rauber, A. Schwarz, and V.V. Michel. 2000. First report of St. John'swort anthracnose caused by Colletotrichum gloeosporioides in Switzerland. Plant Dis. 84: 203.

Gardner, R.G. 1990. Greenhouse disease screen facilitates breeding resistance to tomato early blight. HortScience 25:222-223.

Gaudin, M., X. Simonnet, N. Debrunner, and A. Ryser. 2002. Breeding for a Hypericum perforatum L. variety both productive and
Colletotrichum gloeosporioides (Penz.) tolerant. In: Johnson, C.B. and C. Franz (eds.). Breeding research on aromatic and medicinal plants. Haworth Herbal Press, New York, NY.

Hildebrand, P.H. and K.I.N. Jensen. 1991. Potential for the biological control of St. John's-wort (Hypericum perforatum) with an endemic strain of Colletotrichum gloeosporioides. Can. J. Plant Pathol. 13:60-70.

Kasper, S., F. Caraci, B. Forti, F. Drago, and E. Aguglia. 2010. Efficacy and tolerability of Hypericum extract for the treatment of mild to moderate depression. Eur. Neuropsychopharmacol. 20:747-765.

Lange, D. 2004. Medicinal and aromatic plants: Trade, production and management of botanical resources. In: Craker, L.E., J.E. Simon, A. Jatisatienr, and E. Lewinsohn. (eds.). XXVI International Horticultural Congress: The Future for Medicinal and Aromatic Plants. Toronto, Canada, Acta Hort. 629:177-197.

Little, T.M. and F.J. Hills. 1978. Agricultural Experimentation. Wiley, New York, NY.

$\mathrm{Lu}, \mathrm{H}$. and R. Raid. 2013. A novel screening method for evaluation of lettuce germplasm for bacterial leaf spot resistance. HortScience 48:171-174.

Mártonfi, P., R. Brutovská, E. Čellárová, and M. Repčák. 1996. Apomixis and hybridity in Hypericum perforatum. Folia Geobot. Phytotaxon. 31:389-396.

Mordue, J.E.M. 1971. Glomerella cingulata: C.M.I. Description of pathogenic fungi and bacteria no. 315. Commonwealth Mycological Institute, Surrey, UK.

Müller, W.E. (ed.). 2005. St john's wort and its active principles in depression and anxiety. Birkhäuser, Basel, Switzerland.

Pande, S., M. Sharma, P.M. Gaur, S. Tripathi, L. Kaur, A. Basandrai, T. Khan, C.L.L. Gowda, and K.H.M. Siddique. 2011. Development of screening techniques and identification of new sources of resistance to Ascochyta blight disease of chickpea. Australasian Plant Pathol. 40:149-156.

Plaisted, R.L. and L.C. Peterson. 1959. A technique for evaluating the ability of selections to yield consistently in different locations or seasons. Amer. Potato J. 36:381-385.

Russell, G.E. 1978. Plant breeding for pest and disease resistance. Butterworths, London, UK.

Schenk, R. and U. Gärber. 2002. Colletotrichum cf. gloeosporioides an Johanniskraut (Hypericum perforatum L.). 4. Teil: Resistenzprüfung von Johanniskrautsorten und -stämmen. Nachrichtenblatt des Deutschen Pflanzenschutzdienstes 54:86-91.

Schulte, J., W. Schaffner, B. Büter, and K. Berger Büter. 1999. Kreuzungsexperiemente mit verschiedenen Arten der Gattung Hypericum. Z. Arzn. Gew. Pfl. 4:126-133.

Schwarczinger, I. and L. Vajna. 1998. First report of St. John's-wort anthracnose caused by $\mathrm{Col}$ letotrichum gloeosporioides in Hungary. Plant Dis. 82:711.

Shepherd, R.C.H. 1995. A Canadian isolate of Colletotrichum gloeosporioides as a potential biological control agent for St John's wort (Hypericum perforatum) in Australia. Plant Prot. Q. 10:148-151.

Simonnet, X. and M. Gaudin. 2000. Médiplant, un centre de recherches au service de la filière des plantes médicinales et aromatiques. Rev. Suisse Vitic. Arboric. Hort. 32:357-358.

Yang, X.B. and D.O. TeBeest. 1992. Rain dispersal of Colletotrichum gloeosporioides under simulated rice field conditions. Phytopathology 82 : 1219-1222. 